\title{
Marketing e difusão de inovações por Universidades Federais: estudo multicaso no sul de Minas Gerais
}

\author{
Marketing and Knowledge Diffusion in Federal Universities: Multicase \\ Study in South of Minas Gerais
}

\author{
André Siqueira Rennó ${ }^{1}$, João Francisco Sarno Carvalho ${ }^{2}$, Érica Aline Ferreira Silva ${ }^{3}$ \\ ${ }^{1}$ Centro Universitário de Formiga - UNIFOR-MG, Minas Gerais, Brasil \\ ${ }^{2}$ Universidade Federal de Minas Gerais - UFMG, Belo Horizonte, Minas Gerais, Brasil \\ ${ }^{3}$ Universidade Federal de Lavras - UFLA, Lavras, Minas Gerais, Brasil
}

\begin{abstract}
Resumo
Introdução: Atualmente, existe um direcionamento global ao conceito de universidades como protagonistas de produção do conhecimento e geradoras de inovações tecnológicas. Objetivo: O objetivo desse trabalho foi entender como empresas incubadas em Instituições de Ensino Superior (IES) se apropriam do conhecimento gerado e difundido na Universidade e o aplicam em seus negócios. Metodologia: A metodologia utilizada foi um estudo de caso em quatro empresas de base tecnológicas incubadas em duas IES. Resultados: Verificou-se que o marketing institucional dentro da IES para os conhecimentos gerados ainda é muito imaturo. Não se verificou investimentos em marketing para os projetos desenvolvidos pelas empresas incubadas. Conclusão: Em relação à apropriação da inovação, esse conceito está muito imaturo dentro da cultura da universidade. Não se notou uma grande preocupação com a proteção dos ativos intelectuais por alguns motivos, entre eles: excesso de burocracia para utilização desses mecanismos, por acreditar que outros mecanismos de proteção técnica possam ser mais úteis ao empreendimento e por acreditar que, em se tratando de um ambiente de alta tecnologia, essas não necessitariam de proteção por se modificarem rapidamente nesse ambiente dinâmico.
\end{abstract}

Palavras-chave: Apropriabilidade da Inovação; Difusão de Conhecimento; Gestão do Conhecimento.

Autor correspondente:

André Siqueira Rennó

Endereço: Rua Geraldo Serrano, 1761, apto 201, Bairro São Judas

Tadeu, Divinópolis $(M G)$.

Telefone: +55 (37) 98842-6422

E-mail: andrerenno89@gmail.com

Recebido em: 18/01/2017

Revisado em: 09/03/2017

Aceito em: 06/04/2017

Publicado em: 28/04/2017 


\section{Abstract}

Introduction: Currently there is an overall direction to the concept of universities as production protagonists of knowledge and generators of technological innovations. Objective: The aim of this study was to understand how the incubated companies of federal universities appropriate the knowledge generated and disseminated in the university and apply in their business. Methodology: The methodology used was a case study in four incubated technology-based companies in two federal universities. Results: One discovery was that the institutional marketing within the public university for the knowledge generated is still very immature. The research did not verify investment in marketing to the projects developed by the incubated companies. Conclusion: Regarding the appropriation of innovation, this concept is very immature in the university culture. Another find was a lack of a major concern with the protection of intellectual assets for several reasons, including: excessive bureaucracy to use these mechanisms, believing that other technical protection mechanisms can be more useful to the project and believe that the case of an environment high-tech, these would not need protection because they modify quickly in this dynamic environment.

Keywords: Innovation Apropriability. Knowledge Difusion. Knowledge Management.

\section{Introdução}

$\mathrm{Na}$ atualidade, existe um direcionamento global ao conceito de universidades como protagonistas de produção do conhecimento e geração de inovações tecnológicas. Para atender a essa nova realidade, essas instituições têm sido desafiadas a mudar estruturas tradicionais e a buscar novas estratégias que lhes permitam gerar tecnologias úteis à sociedade ${ }^{1}$. Nesse sentido, quando incorporadas à sociedade, essas tecnologias assumem o status de "inovação", passando a gerar apropriabilidade e um conjunto de benefícios decorrentes do processo de apropriação.

Nesse mesmo contexto, encontra-se a difusão do conhecimento, que, na Era da Informação e do Conhecimento, sofreu as consequências das mudanças operadas na sociedade (globalização, sociedade em rede, aumento da complexidade econômica e ambiental) e, por isso, gerou a necessidade de refletir o papel da ciência sob uma perspectiva mais sistêmica ${ }^{2}$. No novo ambiente, a complexidade dos sistemas de produção de conhecimento científico e da inovação, bem como o seu nível de propagação na sociedade em geral, sugere uma gestão estratégica integrada da ciência. Atualmente, "fazer ciência" não consiste somente em produzir novo conhecimento, mas, ao mesmo tempo, difundir, disseminar e usar o conhecimento e a inovação.

Em busca de promover um melhor gerenciamento das inovações nas universidades, de acordo com a Lei de Inovação $n^{\circ} 10.973 / 04^{3}$, foram criados os Núcleos de Inovação Tecnológica (NITs), com o objetivo de estruturarem as ações e estreitar as relações dos pesquisadores das instituições de ensino superior (IES) com o mercado, com vistas a coordenar processos de registro, proteger os produtos desenvolvidos por pesquisadores, e promover a transferência dessas inovações para a sociedade.

Vinculado ao NIT, está a Incubadora de Empresas de Base Tecnológica, responsável pelo processo de incubação de empresas de base tecnológica e pelo desenvolvimento da cultura empreendedora no âmbito da universidade, incumbida de abrigar empresas cujos produtos, processos ou serviços são gerados a partir de resultados de pesquisas aplicadas, nas quais a tecnologia representa um alto valor agregado.

Outro acontecimento importante para a área da inovação no Brasil ocorreu no início de 2016, com a sansão da lei federal $\mathrm{n}^{\circ} 13.243$, denominada de "Marco Legal da Ciência e Tecnologia e Inovação"4. Essa nova lei permite que as universidades públicas e empresas privadas trabalhem de forma mais próxima, permitindo situações como a autorização para que professores em regime de dedicação integral possam desenvolver pesquisas dentro de empresas e que laboratórios universitários sejam usados pela indústria para o desenvolvimento de novas tecnologias - ambos os casos com remuneração. Outros pontos importantes é a desburocratização do sistema de licitação, compra e importação de produtos destinados à pesquisa científica tecnológica. Essa nova lei demonstra uma evolução do Brasil na aproximação entre universidades e empresas, bem como no fomento à inovação.

Um campo de estudo ainda pouco explorado é a maneira com que as IES buscam difundir suas 
tecnologias desenvolvidas. Tendo em vista que grande parte das empresas incubadas nas Incubadoras

de Empresas de Base Tecnológica surgiram a partir de tecnologias desenvolvidas por essas instituições, o problema de pesquisa definido foi: como as empresas incubadas nas universidades se apropriam de suas inovações e qual a participação dessas instituições no marketing dessas inovações?

Diante do cenário, o objetivo é entender como as empresas incubadas em duas IES situadas no sul de Minas Gerais se apropriam do conhecimento gerado e difundido na Universidade e aplicam em seus negócios. Para tanto, este trabalho foi estruturado em três tópicos que abordarão o tema em foco, além dessa introdução. A seguir, serão apresentados os procedimentos metodológicos; a análise de resultados que contém a contextualização da Incubadora; as discussões teóricas; e por fim, a conclusão deste estudo.

\section{Metodologia}

Devido às características desta investigação em proposição, adota-se a postura metodológica de natureza qualitativa. A principal função da pesquisa qualitativa é a explicação sistemática de fatos que ocorrem no contexto social, geralmente relacionada a uma multiplicidade de variáveis ${ }^{5}$. Para o autor, essa tipologia de pesquisa é apropriada quando se busca estudar a subjetividade, as crenças, os valores, as atitudes, as relações e práticas sociais, as estratégias, os modelos de gestão e as mudanças ocorridas no contexto organizacional, social, político e econômico.

O presente trabalho visa a demonstrar quais as relações das empresas incubadas em duas IES com a gestão do conhecimento, apropriação do conhecimento e estratégias de marketing. Para isso, foi feita uma pesquisa bibliográfica sobre o tema e foi definida como metodologia uma pesquisa de natureza teórico-empírica, com uma abordagem qualitativa do tipo descritiva. O estudo de caso foi o método escolhido, por ser apropriado às intenções exploratórias do estudo ${ }^{6}$.

Inicialmente foi realizada uma pesquisa bibliográfica de literatura a partir de pesquisas envolvendo a área de conhecimento de ciências sociais aplicadas com os termos marketing, inovação e universidade. Dessa forma, foi feita a construção teórica do trabalho com base nos principais autores dessas áreas.

As unidades de análise foram quatro empresas, duas incubadas na Incubadora de Empresas de Base Tecnológica da Universidade Federal de Lavras (Inbatec/UFLA) e duas incubadas na Incubadora de Empresas de Base Tecnológica de Itajubá (Incit/UNIFEI). Os sujeitos da pesquisa foram os gestores de cada empresa incubada, os quais foram entrevistados pessoalmente por meio de um roteiro semiestruturado.

O questionário utilizado nesta pesquisa buscou identificar a realidade do marketing e difusão das inovações pelas empresas incubadas, além do suporte oferecido pela IES nesse processo de divulgação e transferência de tecnologia para a sociedade.

Os pesquisadores foram os condutores da investigação, e a fonte de evidência foi o entrevistado. Duas estratégias gerais de análise, próprias para o método do estudo de caso, são apresentadas: embasamento nas proposições teóricas e descrição do caso $^{6}$. Para tabulação e análise dos dados, utilizou-se análise de conteúdo das entrevistas realizadas e análise de dados secundários, como sites das empresas incubadas.

\section{Resultados}

No Brasil, verifica-se que o recurso "conhecimento" vem aumentando aceleradamente sua importância para o desempenho empresarial e que os desafios impostos pela relativa e recente abertura econômica tornam a questão da gestão do conhecimento ainda mais fundamental para as empresas brasileiras.

A gestão do conhecimento é definida como o processo que cria continuamente novos conhecimentos, os dissemina e os perpetua por toda a organização ${ }^{7}$. Ela também pode ser entendida como a arte de criar valor a partir dos ativos intangíveis das organizações $^{8}$.

A gestão do conhecimento é um esforço para aumentar o conhecimento útil dentro da organização. Existem algumas maneiras de fazer isso como encorajar a comunicação, oferecer oportunidades de aprendizado e promover o compartilhamento apropriado do conhecimento. Essa informação pode ser comprovada pela fala do Entrevistado 1 da pesquisa, que utiliza as diversas ferramentas de gestão do conhecimento e marketing:

"Existem várias saídas produzidas ao longo do projeto: processos, projeto arquitetural do sistema, manter e evoluir o sistema, o próprio documento de requisitos, Road Maping da tecnologia. Tudo isso são ativos da empresa, construídos por base do conhecimento do mercado, conhecimento dos concorrentes, conhecimento do contexto do mercado, conhecimento do que agrega valor para os nossos clientes. Dessa maneira, acaba se desenhando o produto, sabendo o que se deve agregar a esse novo produto ao longo do tempo culminando no software desenvolvido pela empresa." (E1)

O Entrevistado 1 também foi questionado sobre o nível de proteção dos resultados de $\mathrm{P} \& \mathrm{D}$ de sua empresa. Relacionado ao nível de apropriabilidade utilizado pela empresa: 
"Internamente a gente tem com cada colaborador um contrato, um acordo de confidencialidade, registro da marca, o registro do software, domínio que a gente utiliza (...)." (E1)

Segundo o Entrevistado 1, o direito de propriedade intelectual não desempenha papel central no caso da sua empresa. Mas, mesmo assim, afirma que os mecanismos de apropriabilidade que eles utilizam são suficientes para sua proteção. Ele acredita que a principal proteção da empresa não é depender da proteção intelectual, mas, sim, da capacidade de inovar, de entender o contexto e o mercado, além de contar com uma equipe sempre comprometida e de alta performance, a fim de transformar tudo aquilo que se entende que agrega valor e deve ser entregue para o usuário final com melhor experiência e menor tempo possível. Isso vai garantir um dia a liderança do mercado e que seria o diferencial da Empresa 1.

Sobre o processo de gestão do conhecimento e apropriação do conhecimento o Entrevistado 1 afirma que, muitas vezes, a empresa acaba gerando conhecimento e não se apropriando desse conhecimento da forma correta por esse conhecimento não ser corretamente gerenciado dentro da empresa. Sobre o mesmo tema, a empresa ainda está bastante imatura, pois não possui um processo de gestão do conhecimento.

A apropriabilidade diz respeito a algo que pode se tornar próprio; algo que é suscetível de ser apropriado9. Pode ser também a capacidade de impossibilitar a ação de imitadores e de garantir o retorno otimizado dos investimentos de $\mathrm{P} \& \mathrm{D}^{10}$. É interessante analisar que dentro das empresas estudadas, por se tratarem de empresas de tecnologias novas, essas não possuem uma real preocupação com a apropriação de suas tecnologias e conhecimento, por acreditar que seu ativo intelectual seja bastante específico é dificilmente replicado.

As empresas de Tecnologia da Informação, principalmente de software, possuem a característica de oferecer soluções únicas para seus clientes. Por isso, é interessante observar que a Empresa 1 adota uma postura de desenvolvimento reverso de produto. Essa empresa não busca desenvolver um produto e vender no mercado. Mas, como se trata de produtos muito específicos e especializados, primeiramente é feita uma pesquisa de mercado para verificar as necessidades dos clientes, as características do mercado, para depois desenvolver uma solução customizada para ele. Trata-se de uma solução que atenda especificamente a essa demanda, passível de melhoramentos e adaptações futuras e também de acompanhamento contínuo. $\mathrm{O}$ produto final precisa fazer sentido para o mercado.

Tomando por base a segunda entrevista, questionou-se sobre qual a natureza dos ativos de conhecimento gerados pela empresa. O Entrevistado 2 respondeu que a principal natureza dos ativos de conhecimento gerados por essa empresa de base tecnológica são os software e hardware. Já sobre o nível de proteção legal dos resultados, o Entrevistado 2 afirma que a empresa possui uma patente de um de seus produtos, além de proteções mais técnicas. Para ele, os direitos de propriedade intelectual não desempenham um papel central nesse caso, por acreditar que esse setor é bem dinâmico e que os cenários mudam rapidamente.

Segundo o Entrevistado 2, a UFLA poderia divulgar os resultados que são gerados dentro da universidade. Para ele, a universidade não dissemina o conhecimento gerado pelas empresas incubadas interna e/ou externamente. Ainda na visão do entrevistado, isso ajudaria as empresas na forma de agregar conhecimento, bem como na evolução do marketing de conhecimento.

Sobre gestão do conhecimento, o Entrevistado 2 demonstra que a empresa se preocupa com a gestão do conhecimento gerado e disseminado dentro da empresa e afirma que:

“A empresa possui uma base de conhecimento, a gente possui uma wiki (documentação do conhecimento gerado). Além do software e hardware que a empresa produz, a empresa considera como um bem da empresa o conhecimento que está adquirindo e construindo". (E2)

Assim como a Empresa 1, a Empresa 2 também se baseou no mercado para criação e evolução de seus produtos. Segundo o Entrevistado 2:

“A pesquisa resultou num produto que é comercializado, produto que é um sistema integrado a um hardware. Essa apresentou viabilidade técnica e mercadologia alta, sabia que era uma demanda do mercado, a ideia já nasceu embasada no mercado." (E2)

Seguem os quadros comparativos das informações de marketing utilizadas pelas quatro empresas: 
Quadro 1: Informações de Marketing - Empresas Incubadas na Inbatec/UFLA e Incit/UNIFEI

\begin{tabular}{|c|c|c|c|c|}
\hline & EMPRESA 1 (UFLA) & $\begin{array}{l}\text { EMPRESA } 2 \\
\text { (UFLA) }\end{array}$ & $\begin{array}{l}\text { EMPRESA } 3 \\
\text { (UNIFEI) }\end{array}$ & $\begin{array}{l}\text { EMPRESA } 4 \\
\text { (UNIFEI) }\end{array}$ \\
\hline Segmento & $\begin{array}{l}\text { Embarcadores, } \\
\text { transportadores que tem } \\
\text { frota própria, } \\
\text { transportadores } \\
\text { autônomos }\end{array}$ & Agronegócio & $\begin{array}{l}\text { Aplicativos para } \\
\text { Celulares } \\
\text { (Mobile/WEB) }\end{array}$ & $\begin{array}{l}\text { Design para } \\
\text { Engenharia (Acústica, } \\
\text { Vibração e Segurança) }\end{array}$ \\
\hline Principal Mercado & $\begin{array}{l}\text { Transportadores } \\
\text { autônomos }\end{array}$ & Agronegócio & Empresas e eventos & Engenharia \\
\hline $\begin{array}{l}\text { Principal Fonte de } \\
\text { Receita }\end{array}$ & $\begin{array}{l}\text { Taxa paga pelo } \\
\text { transportador }\end{array}$ & $\begin{array}{l}\text { Venda de Software e } \\
\text { Equipamentos }\end{array}$ & $\begin{array}{l}\text { Venda de aplicativos e } \\
\text { venda de pacotes de } \\
\text { serviços }\end{array}$ & $\begin{array}{l}\text { Venda de projetos de } \\
\text { design de produtos }\end{array}$ \\
\hline $\begin{array}{l}\text { Estrutura de Custo } \\
\text { de Produção }\end{array}$ & $\begin{array}{l}\text { P \& D (pesquisa de } \\
\text { mercado, validação } \\
\text { junto ao cliente), custo } \\
\text { de marketing, custo de } \\
\text { infraestrutura em TI }\end{array}$ & $\begin{array}{l}\text { Desenvolvimento de } \\
\text { software, custo da } \\
\text { montagem física dos } \\
\text { equipamentos. Além } \\
\text { dos custos de mão de } \\
\text { obra e matéria prima. }\end{array}$ & $\begin{array}{l}\text { Desenvolvimento de } \\
\text { software, custo de } \\
\text { mão-de-obra }\end{array}$ & Custos de mão-de-obra \\
\hline Geração de receita & $\begin{array}{l}\text { Cobranças de uma taxa } \\
\text { por transação }\end{array}$ & Venda Direta & Venda direta & $\begin{array}{l}\text { Capital intelectual da } \\
\text { empresa }\end{array}$ \\
\hline $\begin{array}{l}\text { Canais de } \\
\text { Distribuição }\end{array}$ & Internet & Venda Direta & $\begin{array}{l}\text { Site, representante } \\
\text { comercial, internet em } \\
\text { geral }\end{array}$ & $\begin{array}{l}\text { Estão procurando } \\
\text { desenvolver com apoio } \\
\text { da Incubadora; }\end{array}$ \\
\hline $\begin{array}{l}\text { Posição na Cadeia } \\
\text { de Valor }\end{array}$ & $\begin{array}{l}\text { Produtora do } \\
\text { produto/serviço }\end{array}$ & $\begin{array}{l}\text { Fabricação, } \\
\text { assistência, venda, } \\
\text { pós-venda }\end{array}$ & $\begin{array}{l}\text { Produtora do } \\
\text { produto/serviço }\end{array}$ & Produtora do produto \\
\hline $\begin{array}{l}\text { Parcerias } \\
\text { Estratégicas }\end{array}$ & $\begin{array}{l}\text { Sindicatos de empresas } \\
\text { de transportes, empresas } \\
\text { de pagamento eletrônico }\end{array}$ & $\begin{array}{l}\text { Laboratórios, Órgãos } \\
\text { de Fomento, } \\
\text { Fornecedores }\end{array}$ & $\begin{array}{l}\text { Mercado de eventos, } \\
\text { Feiras de aplicativo, } \\
\text { Festival Integrado de } \\
\text { Cultura e Arte, } \\
\text { Parceiro na área de } \\
\text { Construção Civil }\end{array}$ & Universidades \\
\hline $\begin{array}{l}\text { Estratégia } \\
\text { Competitiva }\end{array}$ & $\begin{array}{l}\text { Diferenciação de } \\
\text { produto }\end{array}$ & $\begin{array}{l}\text { Nicho e Diferenciação } \\
\text { de produto }\end{array}$ & Nicho e Diferenciação & $\begin{array}{l}\text { Diferenciação, } \\
\text { Liderança em Custo e } \\
\text { Nicho }\end{array}$ \\
\hline $\begin{array}{l}\text { Apropriação } \\
\text { Econômica }\end{array}$ & $\begin{array}{l}\text { Integração Vertical e } \\
\text { Venda }\end{array}$ & Venda & Venda & Venda \\
\hline $\begin{array}{l}\text { Apropriação de } \\
\text { Valor }\end{array}$ & $\begin{array}{l}\text { Buscando no mercado } \\
\text { referência para o } \\
\text { desenvolvimento de um } \\
\text { projeto economicamente } \\
\text { viável }\end{array}$ & $\begin{array}{l}\text { Transformando a } \\
\text { pesquisa e projeto que } \\
\text { foi realizado num } \\
\text { produto que é viável } \\
\text { mercadologicamente. }\end{array}$ & $\begin{array}{l}\text { Elaborando Produtos } \\
\text { para comercialização }\end{array}$ & $\begin{array}{l}\text { Transformando } \\
\text { Projetos em Produtos } \\
\text { para comercialização }\end{array}$ \\
\hline
\end{tabular}

Fonte: Dados da Pesquisa (2015)

Percebe-se que as empresas incubadas na Inbatec/UFLA, por serem de base tecnológica, possuem similaridade. Como é o caso do investimento em P\&D, do desenvolvimento de produtos e serviços que já atendam uma demanda de mercado por possuírem como estratégia competitiva a diferenciação do seu produto em relação do mercado, bem como o mesmo tipo de apropriação econômica, no caso das vendas.

Entretanto, as duas primeiras empresas possuem suas diferenças em relação ao mercado, segmento, principal fonte de receita, canais de distribuição e parcerias estratégicas. Claramente, por atuarem em segmentos diferentes e atenderem a um diferente público-alvo. Mas, por serem empresas de alta tecnologia, possuem certas características em comum.

\section{Discussão}

Nessa sessão, será feita a discussão dos resultados obtidos na pesquisa, contrapondo a teoria já existente sobre o assunto e os resultados 
encontrados no campo de prática. Defende-se que a ciência é uma das formas de conhecimento produzida pelo homem, no decorrer da história, como tentativa de entender e explicar racionalmente a natureza e os fenômenos que nela acontecem ${ }^{1}$. Nessa tentativa, o ser humano busca formular leis e teorias que possam explicar o universo que o cerca. A ciência, enquanto tentativa de explicar a realidade, se caracteriza por ser uma atividade metódica. Como produto social, a ciência se vincula às agendas pessoais, políticas e decisórias $^{10}$ que se unem aos contextos de forma conflitiva dentro das estruturas sociais.

Dessa maneira, enquanto a ciência é o estudo de um fenômeno rigorosamente de acordo com o método científico, a "tecnologia" é a aplicação desse mesmo conhecimento científico para atingir resultados práticos ${ }^{11}$. Entretanto, a tecnologia pode ser abordada conceitualmente em prismas mais amplos. Assim, a tecnologia pode ser vista como "a incorporação de conhecimento (...) tornando possível criar novos produtos, explorar novos mercados, usar novas maneiras de organização, incorporar novas matériasprimas ou utilizar novos processos para atender às necessidades dos clientes"12.

Nesse sentido, as verificou-se que as Empresas objetos desse estudo, além de possuírem a necessidade de divulgar seus produtos e serviços e manterem um relacionamento positivo com clientes internos $\mathrm{e}$ externos, também precisam se proteger de seus ativos intelectuais. A apropriação dos conhecimentos gerados por uma organização, transformando-os em valor, passar a ser imprescindível no contexto competitivo atual. A apropriabilidade são aquelas propriedades do conhecimento tecnológico e artefatos técnicos de mercado e do ambiente legal que possibilitam a captura dos benefícios gerados pelas inovações e a protege, em graus variados, como ativos rentáveis, contra a reprodução ilícita por parte de outros agentes, diferindo entre indústrias e entre tecnologias ${ }^{13}$.

Ao acompanharmos as empresas incubadas na Incit/UNIFEI, notou-se, pelo relatado, que a apropriabilidade de conhecimento gerado pelas empresas possui barreiras. Os gestores entrevistados apontaram a distância física da incubadora do campus universitário como empecilho para maior participação de mão de obra especializada, tanto pelo suporte dos docentes quanto pela oferta de estudantes como mão de obra treinada.

\section{Conclusão}

Em uma sociedade permeada pela globalização e pela rapidez com que as relações sociais são pautadas na ótica do modo de produção capitalista, fez-se pertinente vislumbrar de que modo esses
Ademais, se compararmos as estruturas e o suporte que as incubadoras estudadas (Inbatec/UFLA e Incit/UNIFEI) dão às suas empresas, a Inbatec/UFLA mostrou-se mais preparada a fornecer uma estrutura de desenvolvimento tecnológico. Assim,, permite-se a apropriabilidade e a difusão de conhecimento com maior amplitude do que a incubadora vinculada à UNIFEI.

Vale ressaltar que a apropriabilidade dos ativos de conhecimento das empresas incubadas não é de responsabilidade das universidades, e sim, das empresas, que buscam proteger da maneira que definem como mais adequada. Sobre a apropriabilidade do conhecimento em universidades, verificou-se a existência de diversos mecanismos de apropriação do conhecimento gerado dentro de uma universidade, são os Núcleos de Inovação Tecnológica responsáveis por buscar efetivar a proteção das tecnologias geradas nas IES. Mas essa proteção de conhecimento só será possível se as Empresas incubadas nessas IES tiverem interesse em tal proteção.

Analisando os dados, verifica-se uma carência de investimentos e estratégias para a difusão dos conhecimentos gerados nas duas instituições ${ }^{14}$. Dessa maneira, as empresas incubadas não percebem nas IES um apoio para promoção e divulgação de suas atividades de inovação.

Ao vincular o desenvolvimento econômico com o processo de inovação, tem-se que "inovação consiste na geração de uma nova ideia e a sua implementação em um novo produto, processo ou serviço, que leva a um crescimento dinâmico da economia nacional e no aumento do emprego assim como a criação de lucro para empresas inovadoras"15. Outra concepção está relacionada à ideia de não ser transformada em um produto, processo ou serviço, ou não ser comercializada, não podendo ser classificada, então, com inovação ${ }^{16}$.

Dessa forma, verifica-se que as empresas, além de divulgarem seus produtos e serviços e manterem um relacionamento positivo com clientes internos e externos, também precisam da proteção de seus ativos intelectuais. Dentro desse contexto acadêmico, as IES que possuem empresas incubadas em seus Núcleos de Inovação Tecnológica precisam fomentar ao máximo a divulgação das tecnologias mantidas em sua estrutura, tendo em vista que a inovação não irá acontecer efetivamente caso não haja transferência de tecnologia da universidade para sua aplicação junto à sociedade.

efeitos reverberam na geração de conhecimento e na disseminação de inovações. A partir da elaboração de inovações para além do campo empresarial, notou-se a importância das universidades nesse movimento, 
tornando peça chave para o desenvolvimento brasileiro nas vertentes econômicas e sociais. Entretanto, há um campo científico que pode ser explorado tanto nas áreas de inovação em universidades quanto no marketing dessas instituições, principalmente.

Os dados encontrados permitiram o melhor entendimento da realidade da apropriação da inovação dentro das universidades, da relação da IES com as empresas incubadas, e das necessidades que elas têm para se desenvolver melhor. Por meio dessa análise, permite-se observar que o marketing institucional dentro da IES para os conhecimentos gerados se mostra imaturo. Verificou-se a necessidade de uma maior atuação da universidade para propaganda e disseminação dos conhecimentos, inventos e inovações tecnológicas geradas dentro da IES.

Em relação à apropriação do conhecimento, a pesquisa mostrou que as empresas utilizam dessa ferramenta e apropriam dos conhecimentos gerados por elas, seja por proteção legal, seja por mecanismos técnicos de proteção do conhecimento da empresa. Assim, acreditam estar bem protegidos de terceiros em relação aos ativos do conhecimento que possuem.

Contudo, a não utilização da proteção legal dos ativos intelectuais pode ser vista com um problema contra ações de terceiros. Mesmo que as empresas pesquisadas possuam maior ativo intelectual em sua mão de obra especializada e atuem com uma tecnologia bem específica, é difícil replicar uma maior proteção legal dos ativos, fato interessante para resguardar a propriedade intelectual da empresa incubada.

As empresas estudadas acreditam que um marketing do conhecimento gerado na IES ajudaria, e muito, o desenvolvimento das perspectivas das empresas incubadas. Por ter sido verificada apenas nos objetos pesquisados, essa carência de investimento em marketing ainda precisa ser melhor estudada, é possível a existência desse mesmo cenário em outros setores da universidade.

\section{Declaração de conflitos de interesses}

Os autores do artigo afirmam que não houve nenhuma situação de conflito de interesse, tais como propostas de financiamento, emissão de pareceres, promoções ou participação em comitês consultivos ou diretivos, entre outras, que pudessem influenciar no desenvolvimento do trabalho.
Em conformidade com o objetivo traçado neste trabalho, que buscou entender a relação entre as empresas incubadas nas universidades públicas, a apropriação do conhecimento gerado nesses ambientes e o marketing dessas empresas, conclui-se que ainda existe uma deficiência das IES em relação à difusão dos conhecimentos gerados dentro da universidade.

Não se verificaram investimentos em marketing para os projetos desenvolvidos pelas empresas incubadas. Em relação à apropriação da inovação, esse conceito é analisado de uma perspectiva diferente dentro da cultura das empresas estudadas. Dessa forma, não se notou uma grande preocupação com a proteção dos ativos intelectuais por alguns motivos, entre eles: excesso de burocracia para utilização desses mecanismos; por acreditar que outros mecanismos de proteção técnica possam ser mais úteis ao empreendimento; e por acreditar que, em se tratando de um ambiente de alta tecnologia, não necessitariam de proteção por se modificarem rapidamente em ambiente dinâmico.

Como limitação da pesquisa, verificou-se que o número de empresas entrevistadas foi pequeno, com a possibilidade de ter maior abrangência de entrevistas nas empresas incubadas na IES, para assim extrair um conhecimento mais profundo sobre a realidade dessas empresas. Outra limitação foi a adaptação da metodologia escolhida para a realidade das empresas incubadas, uma vez que alguns entrevistados tiveram dificuldade de responder uma ou outra pergunta do questionário semiestruturado.

Como sugestão para trabalhos futuros, entendemos ser necessária a realização de novos estudos no campo da difusão e apropriação do conhecimento com a intenção de ajudar a evoluir o processo de promoção do conhecimento dentro das universidades. Consequentemente, buscar melhorias na disseminação do conhecimento gerado na IES dentro e fora da instituição. Há de se promover a quebra das barreiras da universidade e permitir o diálogo entre o conhecimento e a sociedade na busca por um desenvolvimento que transcenda somente as égides econômicas.

\section{Referências}

1 - DE BENEDICTO, S. C.; CARVALHO, S.; BITTENCOURT, J. J., ZAMBALDE, A. L.; SILVA FILHO, C. F. D. Apropriação da Inovação em Agrotecnologias: Estudo Multicaso em Universidades Brasileiras. Revista Organizações em Contexto (on-line). Vol. 10, nº 19, 2014, p.181-212.

2 - LÉVY, Pierre. Cibercultura. São Paulo: Editora 34, 1999.

3 - BRASIL. Lei de Inovação, $\mathbf{n}^{\mathbf{0}} \mathbf{1 0 . 9 7 3 ,} 2$ de dezembro de 2004. Disponível em <http://www.planalto.gov.br/ccivil_03/_ato20042006/2004/lei/110.973.htm>. Acesso em 07 jun. 2015. 
4 - BRASIL. Marco Legal da Ciência e Tecnologia e Inovação, Lei $\mathbf{n}^{\circ}$ 13.243, 11 de janeiro de 2016. Dispõe sobre estímulos ao desenvolvimento científico, à pesquisa, à capacitação científica e tecnológica e à inovação. Disponível em <http://www.planalto.gov.br/ccivil 03/ Ato20152018/2016/Lei/L13243.htm>.

Acesso em 01 mar. 2016.

5 - GIL, A. C. Métodos e técnicas de pesquisa social. $5^{\text {a }}$ Ed. São Paulo: Atlas, 2007.

6 - YIN, R. K. Estudo de caso: planejamento e métodos. $4^{\text {a }}$ Ed. Porto Alegre: Bookkman, 2010. 212 p.

7 - NONAKA, I.; TAKEUCHI H. Teoria da criação do conhecimento organizacional. Gestão do conhecimento. Porto Alegre: Bookman, 2008, p.54-90.

8 - SVEIBY, K. E. A nova riqueza das nações. Rio de Janeiro: Editora Campus, 1998.

9 - DIAS, R. de B. A agenda política científica e tecnológica brasileira: uma perspectiva histórica. In: DAGNINO, Renato. Estudos sociais da ciência e tecnologia e política de ciência e tecnologia: abordagens alternativas para uma nova América Latina. Campina Grande: EDUEPB, 2010, p.71-96.

10 - ALMEIDA, M. F. L. de; BARRETO JÚNIOR, J. T.; FROTA, M. N. Apropriação econômica de resultados de P\&D: o caso de uma empresa concessionária de energia elétrica no Brasil. In: CONGRESSO LATINOIBEROAMERICANO DE GESTÃO DE TECNOLOGIA, 2013, Porto. Anais... Porto: ALTEC, 2013.

11 - PIMENTEL, L. O. Propriedade intelectual e inovação. In: BRASIL. Ministério da Agricultura, Pecuária e Abastecimento. Curso de Propriedade intelectual \& inovação no agronegócio. Brasília: MAPA; Florianópolis: EaD/UFSC, 2009, p. 40-97.

12 - SHANE, S. A. Sobre solo fértil: como identificar grandes oportunidades para empreendimentos em alta tecnologia. Tradução de Werner Loeffler. Porto Alegre: Bookman, 2005.

13 - DOSI, G. Sources, procedures and microeconomics effects of innovation. Journal of Economic Literature, Pittsburg. Vol. 26, n 3, 1988, p.1120-1171.

14 - RENNO, A. S.; ZAMBALDE, A. L; VERONEZE, R. B.; SOUSA, D. Propriedade Intelectual e Apropriabilidade em Universidades Federais: Estudo Multicaso no Estado de Minas Gerais. In: SEMINÁRIOS EM ADMINISTRAÇÃO - FEAUSP, 19. , 2016, São Paulo. Anais... São Paulo: USP, 2016.

15 - URABE, K., CHILD, J., KAGONO, T. Innovation and management: International comparisons. Berlin: de Gruyter, 1988.

16 - POPADIUK, S, CHOO, C.W. - Innovation and knowledge creation: how are these concepts related? International Journal of Information Management, 2006. 